\title{
Establishing an Optimal Annealing Process of Magnetic Cores by the Taguchi Method
}

\author{
P. S. Georgilakis ${ }^{(1)}$ \\ N. D. Hatziargyriou ${ }^{(2)}$ \\ N. Logothetis ${ }^{(3)}$ \\ S. S. Elefsiniotis ${ }^{(4)}$

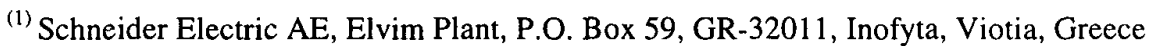 \\ ${ }^{(2)}$ Electric Energy Systems Laboratory, National Technical University of Athens, Greece \\ (3) T.Q.M. Hellas S.A., Athens, Greece \\ ${ }^{(4)}$ New Jersey Institute of Technology, NJ 07102, USA
}

\begin{abstract}
This paper describes the use of statistical methods as advocated by Taguchi to optimize the annealing process of magnetic cores of wound core type transformers. By using orthogonal experimental design and analysis techniques, these methods allow an industrial process to be optimized with only a small number of experiments. Assessment of these experiments differs from conventional methods in that it is of first importance to minimize the variation in response. This then gives a process, which is insensitive to the effects of uncontrollable factors. Results from the application of the optimal conditions in the annealing process of magnetic cores demonstrate the feasibility of this method since it helps reducing core losses as well as the divergence of actual core losses from the theoretical ones.
\end{abstract}

Index Terms - Magnetic cores, annealing process, Taguchi methods.

\section{INTRODUCTION}

High quality products and processes at low cost have become the key to survival in today's global economy. Driven by the need to compete on cost and performance, many quality conscious organizations are increasingly focusing on the optimization of product design.

In case of wound core type transformers, iron losses of individual cores significantly influence the quality (iron losses) of the assembled transformer. Designed at a lower magnetic induction, results in increase of the transformer cost, since more magnetic material is required [1].

In this paper, the first application of Taguchi methods [2,3] for improving the quality of individual cores of wound core type transformers is reported. These methods include tools and concepts of quality improvement that depend heavily on the statistical theory for design of experiments. These methods, also referred to as robust design methods, provide a systematic and efficient approach for conducting experimentation to determine near optimum settings of design parameters for performance and cost. The robust design method uses orthogonal arrays (OA) to study the parameter space, usually containing a large number of controllable (design) and non-controllable (noise) variables, with a small number of experiments. The result of noise factors is either very difficult or even impossible to be controlled. The objective is to determine the appropriate combination of the controllable factors, not only to improve the process, but also to reduce the influence of the noise factors.

In our application, Taguchi methods are applied in order to optimize the annealing process of cores, taking into account the technical characteristics of today's core materials and core designs, parameters very important, if the evolution of standards and materials is considered. Five design factors (parameters) are investigated, namely, annealing final temperature, temperature rising time, furnace opening temperature, duration of constant temperature and protective atmosphere. Each design factor is selected to take two possible values. In addition, after statistical investigation the position of core in the furnace is found to be a noise (noncontrollable) factor. Among the special set of orthogonal arrays, constructed by Taguchi to lay out the product design experiment, the $\mathrm{OA}_{8}$ is selected, requiring only 8 experiments out of 128 . The $\mathrm{OA}_{8}$ array indicates the conditions (values of the five design factors) for each one of the 8 experiments.

Two performance measures are analyzed: the noise performance measure (NPM) and the target performance measure (TPM). These measures aim at the determination of the values of the control (design) factors that improve the quality of cores, and at the same time minimize the influence of the noise factors. Overall, results from the application of Taguchi methods to the transformer core design suggest that the method is a powerful tool that offers simultaneous improvements in quality, cost and engineering productivity.

The paper is organized as follows. Basic terms of the Taguchi approach are presented in Section II. Section III describes the magnetic core production process. The experimental design considered for the optimization of the process as well as the experiment objectives are presented in Section IV. Some data analysis is reported in Section V 
aiming at the achievement of the experiment objectives and the determination of the optimum operating conditions. The future process performance is predicted and compared with the pre-experiment situation in Section VI. Confirmatory experiments, which were conducted under the optimal conditions, are described in Section VII. Conclusions are finally presented in Section VIII.

\section{ThE TAguchI TECHNIQUE}

The techniques that G. Taguchi recommends for reproduction (off-line) quality control $[4,5]$ are based in the traditional statistical design and analysis ideas originated in the West by Fisher, Stewart, Plackett and Burman and others.

Taguchi concentrates his efforts on the minimization of the variability which is caused by the effect of uncontrollable (noise) factors on the response [3]. During controlled experimentation before production, the effects of noise factors are simulated and an optimum combination of easy-tocontrol factors is determined so that robustness (insensitivity to the effects of the noise factors) is achieved.

For designing the experiments, Taguchi recommends the use of "orthogonal arrays"; such designs allow the factors to have different numbers of test settings (levels) and also have the pairwise balancing property: every level of a factor occurs with every level of any of the other factors the same number of times. "Fractional" orthogonal arrays minimize the number of trial runs while keeping the pairwise balancing property $[6]$.

The results of the experimental trials are used to compute statistical performance measures, which quantify quality. An analysis of the noise performance measure (NPM), which is a measure of the process variability, will identify the variability control factors and also their optimal combined setting which could minimise this variability. Also, an analysis of the target performance measure (TPM), which is a measure of the process mean, will reveal which of the controllable factors, that are not variability control factors, have a large effect on the mean response - the target control factors; these can subsequently be used to bring the mean response onto the target value.

An outline of the exploratory steps that we have to take using the available data, so that a proper statistical application of the Taguchi technique can be assured, can be found in [7]. An evaluation and a critique of alternative techniques to fractional experimentation and analysis, in particular those recommended by Dorian Shainin, can be found in [8].

\section{The Magnetic Core Production Process}

To construct a three-phase distribution transformer, two small individual cores (width of core window equal to $F I$ ) and two large individual cores (width of core window equal to $F 2$ ) should be assembled (Fig. 1). The width $F 2$ is in general twice $F 1$. Selection of the most appropriate core constructional parameters is based on the satisfaction of customers' requirements and several technical and economical criteria [9]. The equations for the calculation of the theoretical weight and losses of the small and large individual cores are defined in [10].

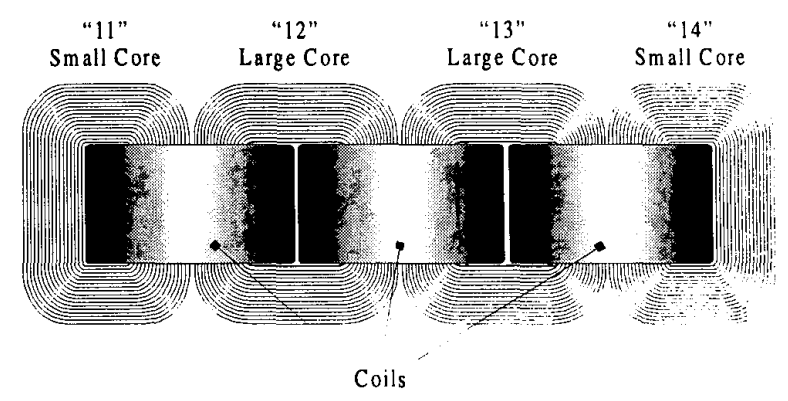

Fig. 1. Assembled active part of wound core distribution transformer.

The production of individual cores includes, at the first stage, the slitting of the magnetic material into bands of standard width. Then, the slit sheets are cut to pre-determined lengths and are wound on a circular mandrel. After that, a suitable press gives a rectangular shape to the circular core. However, the previously described process significantly deteriorates the core characteristics and especially its physical and electrical properties. To restore these properties, annealing follows at temperatures in a range of $760-860^{\circ} \mathrm{C}$ in a protective environment containing pure dry nitrogen mixed with hydrogen up to $2 \%$.

The annealing cycle followed in our application is divided into four stages:

\section{- $\quad$ Starting and heating up stage}

The objective is to avoid oxidation and to normally achieve the temperature of $825{ }^{\circ} \mathrm{C}$. The duration of this cycle is between 2.75 and 3.25 hours. The nitrogen supply for the first hour is $14 \mathrm{~m}^{3} / \mathrm{h}$. For the rest of the period a mixture of $98 \% \mathrm{~N}_{2}$ and $2 \% \mathrm{H}_{2}$ is supplied at a $10 \mathrm{~m}^{3} / \mathrm{h}$ rate.

- $\quad$ Soaking stage

The goal is that all cores in the load must have homogeneous temperature distribution. The duration of this phase is 2.5 hours, at $825{ }^{\circ} \mathrm{C}$. A mixture of $98 \% \mathrm{~N}_{2}$ and $2 \% \mathrm{H}_{2}$ is supplied at a $8 \mathrm{~m}^{3} / \mathrm{h}$ rate.

- $\quad$ Slow cooling stage

The target is to cool the load slowly, in order to avoid the development of internal stresses in the cores. The duration of this cycle is 2 hours. The final temperature is $700{ }^{\circ} \mathrm{C}$. A mixture of $98 \% \mathrm{~N}_{2}$ and $2 \% \mathrm{H}_{2}$ is supplied at a $8 \mathrm{~m}^{3} / \mathrm{h}$ rate. 
- Fast cooling stage

The objective is to reduce the temperature to $380{ }^{\circ} \mathrm{C}$, in order to avoid oxidation of cores, when they are going to be exposed to the environment. The duration of this cycle is 3.5 hours. A mixture of $98 \% \mathrm{~N}_{2}$ and $2 \% \mathrm{H}_{2}$ is supplied at a $8 \mathrm{~m}^{3} / \mathrm{h}$ rate, until the temperature is higher or equal to $600{ }^{\circ} \mathrm{C}$. When the temperature is $600{ }^{\circ} \mathrm{C}$, the supply of $\mathrm{N}_{2}$ is $14 \mathrm{~m}^{3} / \mathrm{h}$.

The total duration of the cycle must not exceed 11.5 hours. The reason is that in a 24 -hours period, it is desirable two annealing cycles to be implemented.

\section{THE EXPERIMENTAL DESIGN}

In our application, Taguchi methods are applied in order to optimise the annealing process of cores. Five controllable variables were identified as potentially important:

PRA: Protective atmosphere (\% content of $\mathrm{H}_{2}$ in the mixture of $\mathrm{N}_{2}$ and $\mathrm{H}_{2}$ )

DCT: Duration of constant temperature (in hours)

TRT: Temperature rising time (in hours)

AFT: Annealing final temperature (in ${ }^{\circ} \mathrm{C}$ )

FOT: Furnace opening temperature (in ${ }^{\circ} \mathrm{C}$ )

For each of the controllable variables two possible levels were considered, as shown in Table I. The five variables were assigned to the $\mathrm{OA}_{8}$ orthogonal design, as shown in Table II. This is a fractional and efficient design for dealing with up to seven two-level factors using only eight experimental trials.

TABLE I

CONTROLLABLE VARIABLES AND THEIR LEVELS

\begin{tabular}{lll} 
& \multicolumn{2}{l}{ Levels } \\
\cline { 2 - 3 } Factor & 1 & 2 \\
\hline PRA & $2 \% \mathrm{H}_{2}$ (and $\left.98 \% \mathrm{~N}_{2}\right)$ & $0 \% \mathrm{H}_{2}\left(\right.$ and $\left.100 \% \mathrm{~N}_{2}\right)$ \\
DCT & 2 hours & 3 hours \\
TRT & 3 hours & 4 hours \\
AFT & $825^{\circ} \mathrm{C}$ & $855^{\circ} \mathrm{C}$ \\
FOT & $250^{\circ} \mathrm{C}$ & $350^{\circ} \mathrm{C}$ \\
\hline
\end{tabular}

TABLE II

$\mathrm{OA}_{8}$ ORTHOGONAL ARRAY (THE VALUES IN PARENTHESES REPRESENT THE FACTOR LEVELS)

\begin{tabular}{|c|c|c|c|c|c|}
\hline \multirow[b]{3}{*}{ Trial } & \multicolumn{5}{|l|}{ Factors } \\
\hline & PRA & DCT & TRT & AFT & FOT \\
\hline & 1 & 2 & 3 & 4 & 5 \\
\hline 1 & $2 \% \mathrm{H}_{2}(1)$ & 2 hours (1) & 3 hours (1) & $825^{\circ} \mathrm{C}(1)$ & $250^{\circ} \mathrm{C}(1)$ \\
\hline 2 & $2 \% \mathrm{H}_{2}(1)$ & 2 hours (1) & 3 hours (1) & $855^{\circ} \mathrm{C}(2)$ & $350^{\circ} \mathrm{C}(2)$ \\
\hline 3 & $2 \% \mathrm{H}_{2}(1)$ & 3 hours (2) & 4 hours (2) & $855^{\circ} \mathrm{C}(2)$ & $350^{\circ} \mathrm{C}(2)$ \\
\hline 4 & $2 \% \mathrm{H}_{2}(1)$ & 3 hours (2) & 4 hours (2) & $825^{\circ} \mathrm{C}(1)$ & $250^{\circ} \mathrm{C}(1)$ \\
\hline 5 & $0 \% \mathrm{H}_{2}(2)$ & 2 hours (1) & 4 hours (2) & $825^{\circ} \mathrm{C}(1)$ & $350^{\circ} \mathrm{C}(2)$ \\
\hline 6 & $0 \% \mathrm{H}_{2}(2)$ & 2 hours (1) & 4 hours (2) & $855^{\circ} \mathrm{C}(2)$ & $250^{\circ} \mathrm{C}(1)$ \\
\hline 7 & $0 \% \mathrm{H}_{2}(2)$ & 3 hours (2) & 3 hours (1) & $855^{\circ} \mathrm{C}(2)$ & $250^{\circ} \mathrm{C}(1)$ \\
\hline 8 & $0 \% \mathrm{H}_{2}(2)$ & 3 hours (2) & 3 hours (1) & $825^{\circ} \mathrm{C}$ (1) & $350^{\circ} \mathrm{C}(2)$ \\
\hline
\end{tabular}

All tests were done using the same $160 \mathrm{kVA}$ transformer design and the same supplier of core magnetic material. The magnetic steel was of grade M3, according to USA AISI, 1983, with thickness $0.23 \mathrm{~mm}$. For every one of the eight experimental trials of Table II, 96 (48 small and 48 large) individual cores were constructed. According to this experimental design, 768 measurements were collected in total. It should be noticed that all cores were annealed at the same furnace.

For each of the 768 measurements, the following data were kept:

- The values of the five controllable factors PRA to FOT.

- The position ("POSITION") of the core in the furnace, which has two possible values: up, or down.

- The theoretical weight of core ("DES_KG") in kg, which takes two possible values: $65 \mathrm{~kg}$ for small cores, or $74.5 \mathrm{~kg}$ for large cores (for the $160 \mathrm{kVA}$ transformer design considered).

- The actual weight of core ("MEAS_KG") in $\mathrm{kg}$, as it was measured using an industrial weighing machine with four load cells and serial RS 232 output for transferring data to a PC.

- The theoretical core losses ("DES_WATT") in Watt, which takes two possible values: 46.8 Watt for small cores, or 53.6 Watt for large cores (for the $160 \mathrm{kVA}$ transformer design considered).

- The actual core losses ("MEAS_WATT") in Watt, as they were measured using one single-phase power analyzer with RS 232 output for transferring measurements to a computer.

The objectives of the experiment were as follows:

01: To determine if the position of the core in the furnace is related with core losses, i.e. if the factor "POSITION" is important for the actual core losses.

O2: To determine the relation between the actual weight of core and the core losses.

O3: To determine the significance as well as the appropriate combination of the five controllable factors considered (i.e. PRA, DCT, TRT, AFT and FOT) in order to simultaneously achieve:

a. The lowest possible actual core losses.

b. The smallest possible divergence between theoretical and actual core losses (MEAS_WATT - DES_WATT).

c. The lowest possible variability in core loss measurements for any given production condition. This variability is the result of noise factors. Such factors can be the position of core in the furnace, the divergence between actual and theoretical weight of core, the environmental conditions, the lack of attention by the handlers, etc. 
The variability (low or high) in core loss measurements for each specific production condition (i.e., for each combination of the controllable factors) represents the influence (low or high) of the noise factors on the production. The objective is to determine the appropriate combination of the controllable factors, not only to reduce core losses, but also to reduce the variability in measurements, i.e. the influence of the noise factors.

O4: Having succeeded in the objective O3, to determine statistical models that predict the average variability in measurements as well as the actual core losses and the divergence between theoretical and actual values, for each specific production condition, determined by the values of the five controllable factors PRA to FOT, for a given weight of core.

\section{ANALYSIS OF THE EXPERIMENTAL DATA}

\section{A. Achievement of Objectives $\mathrm{O} 1$ and $\mathrm{O} 2$}

Taking into account all 768 measurements of the experiment for core losses as well as the actual values of the controllable factors PRA to FOT and the actual weight of each core, the method of multiple regression analysis [7] is used for the determination of the significance of each factor in relation with the actual core losses and in relation with the divergence between the theoretical and actual losses (DIFF = MEAS_WATT - DES_WATT).

The results of the regression analysis are presented in Tables III and IV.

TABLE III

LINEAR REGRESSION ANALYSIS FOR THE ACTUAL CORE LOSSES

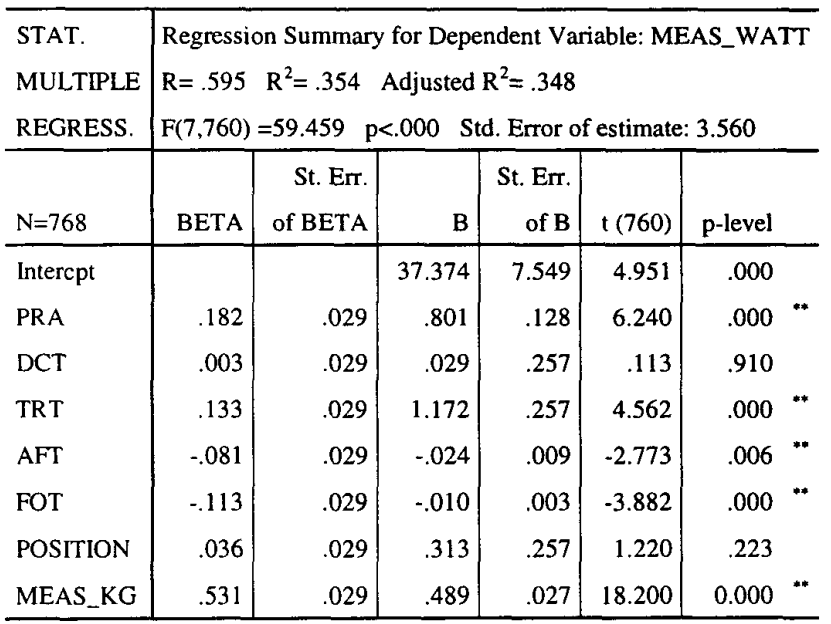

*: statistical significant factor
TABLE IV

LINEAR REGRESSION ANALYSIS FOR THE DIFFERENCE BETWEEN THE ACTUAL AND THE THEORETICAL CORE LOSSES

\begin{tabular}{|c|c|c|c|c|c|c|c|}
\hline $\begin{array}{l}\text { STAT. } \\
\text { MULTIPLE } \\
\text { REGRESS. }\end{array}$ & \multicolumn{7}{|c|}{$\begin{array}{l}\text { Regression Summary for Dependent Variable: DIFF } \\
R=.412 \quad R^{2}=.170 \quad \text { Adjusted } R^{2}=.162 \\
F(7,760)=22.169 \quad p<.000 \quad \text { Std. Error of estimate: } 3.484\end{array}$} \\
\hline$N=768$ & BETA & $\begin{array}{r}\text { St. Err. } \\
\text { of BETA }\end{array}$ & B & $\begin{array}{r}\text { St. Err. } \\
\text { of B }\end{array}$ & $t(760)$ & p-level & \\
\hline Intercpt & & & 35.481 & 7.390 & 4.801 & .000 & \\
\hline PRA & .211 & .033 & .802 & .126 & 6.376 & .000 & ** \\
\hline DCT & .000 & .033 & .000 & .251 & .000 & 1.000 & \\
\hline TRT & .159 & .033 & 1.209 & .251 & 4.806 & .000 & ** \\
\hline AFT &. .091 & .033 & -.023 & .008 & -2.738 & .006 & $*$ \\
\hline FOT & -.133 & .033 &. .010 & .003 & -4.035 & .000 & ** \\
\hline POSITION & .0389 & .033 & .295 & .251 & 1.174 & .241 & \\
\hline MEAS_KG & -.270 & .033 & -.215 & .026 & -8.166 & .000 & ** \\
\hline
\end{tabular}

**: statistical significant factor

Based on the results of Tables III and IV, the factor DCT (duration of constant temperature) and the position of core in the furnace ("POSITION") are not statistically significant factors for the core losses.

The most significant factors for the core losses and for the divergence are primarily the weight of core and the protective atmosphere (PRA), and to lower extent, the temperature rising time (TRT), the furnace opening temperature (FOT) and the annealing final temperature (AFT).

It can be seen from Tables III and IV that, while the five controllable factors and the "POSITION" have a similar effect on the core losses and the divergence, the effect of the weight of core on the core losses is opposite than on the divergence. In other words, when the weight of core is decreased, the core losses are decreased, but the divergence between the theoretical and actual losses is increased and vice versa. Consequently, the theoretical model used [10] for the determination of core losses has better predictability for larger weight of core than for smaller.

As far as the other factors are concerned, they influence the MEAS_WATT and DIFF in a similar way. The factors DCT and "POSITION" do not influence neither the MEAS_WATT nor the DIFF, as long as the AFT and the FOT are increased the MEAS_WATT and the DIFF are decreased, and as long as the TRT and the PRA are decreased the MEAS_WATT and the DIFF are decreased.

Consequently, the optimum conditions for lower core losses are (PRA, TRT, AFT, FOT, MEAS_KG) $=\left(0 \% \mathrm{H}_{2}, 3\right.$ hours, $855{ }^{\circ} \mathrm{C}, 350{ }^{\circ} \mathrm{C}, 65 \mathrm{~kg}$ ), while the optimum conditions for lower divergence between theoretical and actual core losses are (PRA, TRT, AFT, FOT, MEAS_KG) $=\left(0 \% \mathrm{H}_{2}, 3\right.$ hours, $855^{\circ} \mathrm{C}, 350^{\circ} \mathrm{C}, 74.5 \mathrm{~kg}$ ).

The common point in the above conclusions is the nonsignificance of the factors DCT and "POSITION", as well as 
the significance of factors PRA, TRT, AFT and FOT, and in particular the importance of the values (PRA, TRT, AFT, FOT $)=\left(0 \% \mathrm{H}_{2}, 3\right.$ hours, $\left.855^{\circ} \mathrm{C}, 350{ }^{\circ} \mathrm{C}\right)$ regardless of the weight of core.

\section{B. Achievement of Objective $\mathrm{O3}$}

Having already proven that the factor "POSITION" is not significant and as it can be considered as "noise factor", its existence from now on will be ignored.

For the achievement of the objective $\mathrm{O} 3$ the method suggested by Taguchi is used, i.e. the following are determined:

1. which of the five controllable factors PRA to FOT and the weight of core (MEAS_KG) influence the average value of the actual core losses and its divergence from the theoretical core losses, i.e. the target control factors [3] and their optimal positions in order to achieve the target are determined,

2. which of the five controllable factors PRA to FOT and the MEAS_KG influence the variability of the values in every production condition, i.e. the variability control factors and their optimal positions are determined, in order to consistently achieve the target regardless of the influence of the noise factors.

In this case, the experimental design of $\mathrm{OA}_{8}$ is repeated once again in order to take into consideration the factor "core weight" (MEAS_KG). More specifically, the first 8 combinations correspond to the $\mathrm{OA}_{8}$ design for the 384 small cores, while the other 8 combinations correspond to the same $\mathrm{OA}_{8}$ design for the 384 large cores.

1) Choice of performance measures: According to Taguchi method, two performance measures should be studied:

1. The noise performance measure (NPM), which reflects the variation in the response at each setting and its analysis will determine the controllable factors which can affect (and thus control) this variation (the variability control factors). The optimal combined setting of these factors to minimise the variability (and so the effect of the noise factors) will also be determined.

2. The target performance measure (TPM), which reflects the process average performance at each setting and its analysis will reveal those controllable factors which are not variability control factors but have a strong effect on the mean response - the target control factors. These can be manipulated to bring the mean response onto the required target.

The classical pre-Taguchi approach concentrated on the statistical analysis of only the TPM, resulting in unjustified tampering with factors which, although significant for the mean, also affected the variability.

As a target performance measure (TPM), the sample mean of core losses in each trial is used.
Due to reasons described in [11], the appropriate noise performance measure is:

$$
N P M=-10 \log _{10}\left(S^{2}\right),
$$

where $S$ is the standard deviation of measurements of each trial.

The target is to find out the factors and their settings that maximize NPM and minimize TPM.

2) TPM analysis for core losses: Table $V$ presents the TPM analysis for core losses. As expected, the results are similar to the results of Table III for the MEAS_WATT in the way that factors PRA, TRT, AFT, FOT and MEAS_KG significantly affect the mean value of core losses (the target control factor).

Table VI shows the mean core losses for each level of the factors under consideration. From the analysis of Table VI it can be concluded that the optimum combination for these five factors is (PRA, TRT, AFT, FOT, MEAS_KG) $=\left(0 \% \mathrm{H}_{2}, 3\right.$ hours, $855^{\circ} \mathrm{C}, 350{ }^{\circ} \mathrm{C}, 65 \mathrm{~kg}$ ) providing lower core losses. The same result is obtained from the analysis of Table III for the factor MEAS_WATT.

TABLE V

TPM ANALYSIS FOR CORE LOSSES

\begin{tabular}{|c|c|c|c|c|c|c|c|}
\hline $\begin{array}{l}\text { STAT. } \\
\text { MULTIPLE } \\
\text { REGRESS. }\end{array}$ & \multicolumn{7}{|c|}{$\begin{array}{l}\text { Regression Summary for Dependent Variable: } T P M \\
R=.988 \quad R^{2}=.977 \quad \text { Adjusted } R^{2}=.966 \\
F(5,10)=85.420 \quad p<.000 \quad \text { Std. Error of estimate: } .522\end{array}$} \\
\hline $\mathrm{N}=16$ & BETA & $\begin{array}{l}\text { St. Err. } \\
\text { of BETA }\end{array}$ & B & $\begin{array}{l}\text { St. Err. } \\
\text { of B }\end{array}$ & $t(10)$ & p-level & \\
\hline Intercpt & & & 35.415 & 7.647 & 4.631 & .001 & \\
\hline PRA & .294 & .0478 & .801 & .130 & 6.144 & .000 & $* *$ \\
\hline TRT & .220 & .0478 & 1.200 & .261 & 4.600 & .001 & ** \\
\hline $\mathrm{AFT}$ & -.127 & .0478 & -.023 & .009 & -2.659 & .024 & $*$ \\
\hline FOT & -.185 & .0478 & -.010 & .003 & -3.873 & .003 & \\
\hline MEAS_KG & .890 & .0478 & .511 & .027 & 18.604 & .000 & \\
\hline
\end{tabular}

": statistical significant factor

TABLE VI

LEVEL AVERAGES FOR THE CORE LOSSES

\begin{tabular}{lll}
\hline & \multicolumn{2}{l}{ Levels } \\
\cline { 2 - 3 } Factor & 1 & 2 \\
\hline PRA & 54.39 Watt $\left(2 \% \mathrm{H}_{2}\right)$ & 52.79 Watt $\left(0 \% \mathrm{H}_{2}\right)$ \\
TRT & 52.99 Watt $(3$ hours $)$ & 54.19 Watt $(4$ hours $)$ \\
AFT & 53.94 Watt $\left(825^{\circ} \mathrm{C}\right)$ & 53.25 Watt $\left(855^{\circ} \mathrm{C}\right)$ \\
FOT & 54.10 Watt $\left(250^{\circ} \mathrm{C}\right)$ & 53.09 Watt $\left(350^{\circ} \mathrm{C}\right)$ \\
MEAS_KG & 51.17 Watt $(65 \mathrm{~kg})$ & 56.02 Watt $(74.5 \mathrm{~kg})$ \\
\hline
\end{tabular}


3) NPM analysis: Table VII presents the results of the NPM analysis. From the analysis of Table VII it is concluded that the only factors that affect the variability in core losses (the variability control factors) are the DCT and AFT. Table VIII presents the multiple regression model of NPM, using only the variability control factors DCT and AFT.

Using the NPM model of Table VIII and calculating the mean NPM for each level of the variability control factors DCT and AFT it can be concluded that the optimum settings for the DCT and AFT are (DCT, AFT) $=\left(2\right.$ hours, $\left.855^{\circ} \mathrm{C}\right)$.

Consequently, based on the analysis of Table $\mathrm{V}$ (for the TPM) and Table VII (for the NPM) it is concluded that for the reduction of core losses and their variability, the overall optimum combination is (PRA, DCT, TRT, AFT, FOT, MEAS_KG $)=\left(0 \% \mathrm{H}_{2}, 2\right.$ hours, 3 hours, $855^{\circ} \mathrm{C}, 350^{\circ} \mathrm{C}, 65$ $\mathrm{Kg}$ ).

It should be noticed that the above optimal combination of factors is not included in the experimental design considered, since the optimum combination does not belong in the 8 combinations of Table II. This fact indicates the importance of advanced statistical methods, i.e., they are able to find out the statistical optimum combination of controllable factors even if this combination does not belong to the combinations tested during the experiment.

TABLE VII

NPM ANALYSIS

\begin{tabular}{|c|c|c|c|c|c|c|c|}
\hline STAT. & \multicolumn{7}{|c|}{ Regression Summary for Dependent Variable: NPM } \\
\hline MULTIPLE & \multicolumn{7}{|c|}{$\mathrm{R}=.769 \mathrm{R}^{2}=.591 \quad$ Adjusted $\mathrm{R}^{2}=.319$} \\
\hline REGRESS. & \multicolumn{7}{|c|}{$F(6,9)=2.170 \quad p<.143 \quad$ Std. Error of estimate: 2.650} \\
\hline$N=16$ & BETA & $\begin{array}{r}\text { St. Err. } \\
\text { of BETA }\end{array}$ & B & $\begin{array}{r}\text { St. Err. } \\
\text { of B }\end{array}$ & $t(9)$ & p-level & \\
\hline Intercpt & & & -88.790 & 38.990 & -2.277 & .049 & \\
\hline PRA & .056 & .213 & .174 & .663 & .262 & .799 & \\
\hline DCT & -.529 & .213 & -3.289 & 1.325 & -2.482 & .035 & *** \\
\hline TRT & -.121 & .213 & -.750 & 1.325 & -.566 & .585 & \\
\hline AFT & .517 & .213 & .107 & .0442 & 2.424 & .038 & ** \\
\hline FOT & -.154 & 213 & -.010 & .013 & -.721 & 489 & \\
\hline MEAS_KG & .057 & 213 & .037 & .139 & .268 & .795 & \\
\hline
\end{tabular}

$"$ : statistical significant factor

TABLE VIII

MULTIPLE REGRESSION MODEL OF NPM USING DCT AND AFT

\begin{tabular}{|c|c|c|c|c|c|c|}
\hline STAT. & \multicolumn{6}{|c|}{ Regression Summary for Dependent Variable: NPM } \\
\hline MULTIPLE & \multicolumn{6}{|c|}{$\mathrm{R}=.739 \quad \mathrm{R}^{2}=.547 \quad$ Adjusted $\mathrm{R}^{2}=.477$} \\
\hline REGRESS. & \multicolumn{6}{|c|}{$F(2,13)=7.840 \quad p<.006 \quad$ Std. Error of estimate: 2.322} \\
\hline$N=16$ & BETA & $\begin{array}{r}\text { St. Err. } \\
\text { of BETA }\end{array}$ & B & $\begin{array}{r}\text { St. Err. } \\
\text { of } B\end{array}$ & $t(13)$ & p-level \\
\hline Intercpt & & & -91.504 & 32.641 & -2.803 & .015 \\
\hline DCT & -.529 & .187 & -3.289 & 1.161 & -2.833 & .014 \\
\hline AFT & .517 & .187 & 107 & .039 & 2.767 & .016 \\
\hline
\end{tabular}

4) TPM analysis for core loss divergence: In order to analyse the target performance measure (TPM) for the divergence between the theoretical and actual core losses (DIFF), the Taguchi method is once more used. The obtained results are shown in Table IX and are similar with the results of Table $\mathrm{V}$ regarding the significance of the design factors. The only difference is that the influence of the weight in the average core loss divergence is opposite to the influence of weight in the average core losses.

TABLE IX

TPM ANALYSIS FOR CORE LOSS DIVERGENCE

\begin{tabular}{|c|c|c|c|c|c|c|}
\hline STAT. & Regressi & n Summary & for Depe & adent $\mathrm{Va}$ & able: Ml & AN_D \\
\hline MULTIPLE & $R=.965$ & $\mathrm{R}^{2}=.932$ & Adjusted & $k^{2}=.898$ & & \\
\hline REGRESS. & $F(5,10)=$ & $27.348 \quad \mathrm{p}<$ & 00002 & td. Error & f estima & .522 \\
\hline$N=16$ & BETA & $\begin{array}{r}\text { St. Err. } \\
\text { of BETA }\end{array}$ & B & $\begin{array}{r}\text { St. Err. } \\
\text { of B }\end{array}$ & $t(10)$ & p-level \\
\hline Intercpt & & & 35.141 & 7.647 & 4.595 & .001 \\
\hline PRA & .507 & .083 & .801 & .130 & 6.144 & .000 \\
\hline TRT & .380 & .083 & 1.200 & .261 & 4.600 & .001 \\
\hline AFT & -.220 & .083 & -.023 & .009 & -2.659 & .024 \\
\hline FOT & -.320 & .083 & -.010 & .003 & -3.873 & .003 \\
\hline MEAS_KG & -.616 & .083 & -.205 & .027 & -7.468 & .000 \\
\hline
\end{tabular}

Once again, the conclusion is that the smaller core weights influence negatively the predictability of the model used for the theoretical estimation of core losses. In other words, for larger core weights the core loss divergence is smaller and the core loss predictability is better.

It should be noticed that there is no need to analyse a noise performance measure for the core loss divergence since it has been observed that the measurements of the variability in the core loss divergence are exactly the same with the variability in core losses. Consequently, the NPM for the core loss divergence concurs with the NPM for the core losses.

The main conclusions are the following:

1. In order to systematically have low core losses and low divergence between the theoretical and actual core losses, as well as the smaller possible influence of noise factors, the overall optimum process setting is:

(PRA, DCT, TRT, AFT, FOT) $=\left(0 \% \mathrm{H}_{2}, 2\right.$ hours, 3 hours, $855^{\circ} \mathrm{C}, 350{ }^{\circ} \mathrm{C}$ ).

2. The core weight significantly affects results. This influence is positive for the core losses (smaller weights, smaller losses) but negative for the core loss divergence (smaller weights, larger divergence).

\section{Achievement of Objective $\mathrm{O} 4$}

A statistical model for the prediction of the average core losses MEAN_L is obtained from the multiple regression analysis of Table $\mathrm{V}$. This prediction model is described from the coefficients of column $B$ of Table $\mathrm{V}$ as follows: 


$$
\begin{aligned}
\text { MEAN_L }= & 35.415+0.801 * P R A+1.200 * T R T-0.023 * A F T- \\
& -0.010 * F O T+0.511 * M E A S_{-} K G
\end{aligned}
$$

Using the above model, the predicted average core losses in the optimum process setting for a given weight of core can be calculated as follows:

- for weight of core: $65 \mathrm{~kg}, M E A N_{-} L=48.9$ Watt

- for weight of core: $74.5 \mathrm{~kg}, M E A N_{-} L=53.8$ Watt .

One statistical model for the prediction of the average divergence MEAN_D (between theoretical and actual core losses) is obtained from the multiple regression analysis of Table IX:

$$
\begin{gathered}
\text { MEAN_D }=35.141+0.801 * P R A+1.200 * T R T-0.023 * A F T- \\
-0.010 * F O T-0.205 * M E A S_{-} K G
\end{gathered}
$$

Using the above model in the optimum process setting and for a given weight of core, the predicted average divergence between the theoretical and actual core losses can be calculated as follows:

- for weight of core: $65 \mathrm{Kg}, M E A N_{-} D=2.13$ Watt

- for weight of core: $74.5 \mathrm{Kg}, M E A N_{-} D=0.18$ Watt .

Finally, a statistical model for the prediction of the average variability in measurements (i.e. the NPM) is obtained from Table VIII:

$$
N P M=-91.504-3.289 * D C T+0.107 * T R T \text {. }
$$

Therefore, regardless of the weight of core and the other factors (PRA, AFT, FOT), the expected variability in measurements under the optimal conditions $(D C T, T R T)=(2$ hours, $855{ }^{\circ} \mathrm{C}$ ) is calculated as follows:

$$
\begin{gathered}
-10 * \log _{10} S^{2}=-91.504-3.289 * 2+0.107 * 855 \Rightarrow \\
\Rightarrow S=2.116
\end{gathered}
$$

so the expected standard deviation of measurements is $\mathrm{S}=2.116$.

\section{COMPARISON WITH THE PRE-EXPERIMENT SITUATION}

The cores used in Taguchi experiment were made from magnetic material of grade $\mathrm{M} 3$ and thickness $0.23 \mathrm{~mm}$, supplied from SUP_A (supplier A). Using the same magnetic material (grade, thickness and supplier) 1204 small and 1204 large cores were constructed (before the Taguchi experiment).

Table $\mathrm{X}$ presents the average losses and the average variability of these small and large cores. For example, the average losses of the small cores are 50.5 Watt, while the theoretical expected losses are 46.8 Watt, i.e. 3.7 Watt average divergence (before the Taguchi experiment).

The after-experiment expected values in the optimum process setting are also presented in Table X, together with the expected improvement. For example, the average expected losses of the small cores are 48.9 Watt, i.e. $3.2 \%$ lower than the average losses before the Taguchi experiment.
TABLE $X$

EXISTING AND AFTER-EXPERIMENT EXPECTED SITUATION

\begin{tabular}{lll|ll}
\hline & \multicolumn{2}{l|}{ Small cores } & \multicolumn{2}{l}{ Large cores } \\
\cline { 2 - 5 } & Average & Variability & Average & Variability \\
\hline $\begin{array}{l}\text { Losses before } \\
\text { experiment (Watt) }\end{array}$ & 50.5 & 3.841 & 55.6 & 3.866 \\
$\begin{array}{l}\text { Expected losses after } \\
\text { experiment (Watt) }\end{array}$ & 48.9 & 2.116 & 53.8 & 2.116 \\
Improvement (\%) & 3.2 & 44.9 & 3.2 & 45.3 \\
\hline
\end{tabular}

It can be seen from Table $X$ that regardless of the size of core, in the suggested optimum process setting the expected after the experiment core losses, are fairly better (lower) of almost 2 units, while the expected variability is improved by $45 \%$. Furthermore, the expected average divergence between the theoretical and actual core losses is improved by $42 \%$ for the small cores and $91 \%$ for the large cores.

\section{CONFIRMATION}

Results from the application of the optimal conditions in the production process of magnetic cores have demonstrated the feasibility of the Taguchi method.

In particular, adequate measurements were collected after the application of the optimal conditions. Based on the analysis of these measurements, it has been concluded that in all cases the improvement (reduction) in core losses is between $2.7 \%$ and $3.1 \%$. This is viewed as a significant process improvement in an area where even a $1 \%$ core loss reduction is considered of paramount importance. Furthermore, the improvement in variability of losses is between $32 \%$ and $42 \%$. Finally, the reduction (improvement) in the divergence of actual core losses from the theoretical ones is between $30 \%$ and $38 \%$.

\section{CONCLUSIONS}

According to the conventional "change-one-factor-at-atime" method of experimentation, the engineer observes the results of an experimental trial having changed the setting of only one factor while keeping every other factor fixed. For the results of such an experiment to be of any statistical value, one needs all the experimental trials (the combinations of all the levels of the design factors) to be carried out; in our case a forbidding large number of 128 experiments must be conducted.

The experimental design proposed by Taguchi (i.e., a systematic approach for changing many factors simultaneously) reduces the cost of experimentation to a minimum ( 8 experiments instead of 128), while the suggested performance measures TPM and NPM aim at the determination of the levels of the control factors that improve the process (lower core losses) and at the same time minimize 
the influence of the noise factors (i.e., the position of core in the furnace, the divergence between the theoretical and actual weight of core, etc.).

Confirmatory experiments under the optimum conditions have shown a significant decrease in the divergence between the theoretical and actual core losses, aiming at quality improvement and cost reduction of the produced transformer cores.

\section{ACKNOWLEDGMENTS}

The authors would like to thank the General Secretariat of Research and Technology of Greece for financing the research programme entitled "Development of a Quality Control System of Distribution Transformer Magnetic Cores Using Artificial Intelligence Techniques" within the YPER '94 Research Programme. Help from Schneider Electric AE staff in collecting industrial measurements is gratefully acknowledged.

\section{REFERENCES}

[1] B.W. McConnell, "Increasing Distribution Transformer Efficiency: Potential for Energy Savings," IEEE Power Engineering Review, vol 18 , no. 7, pp. 8-10, July 1998

[2] G. Taguchi, Introduction to Quality Engineering. Asian Productivity Organization, 1986

[3] G. Taguchi, Systems of Experimental Design. Vols. 1 and 2, Unipub Kraus International Publishers, New York, 1987.

[4] G. Taguchi and Y. -I. Wu, Introduction to Off-line Quality Control. American Supplier Institute, Dearborn, Michigan, 1985

[5] R.N. Kackar, "Off-line quality control, parameter design and the Taguchi method," Journal of Quality Technology, vol. 17, no. 4, pp. 176-188, 1985.

[6] R.L. Plackett and J.P. Burman, "The design of optimum multifactorial experiments," Biometrica, vol. 33, pp. 305-325, 1946.

[7] N. Logothetis, Managing for Total Quality. Prentice Hall International, UK, 1992.

[8] N. Logothetis, "Alternatives to fractional experimentation: an assessment and critique," Total Quality Management, vol. 1, pp. 335344,1990

[9] P.S. Georgilakis, "Contribution of artificial intelligence techniques in the reduction of distribution transformer iron losses," $P h D$ thesis, National Technical University of Athens, Athens, Greece, March 2000.

[10] N.D. Hatziargyriou, P.S. Georgilakis, D.S. Spiliopoulos, and J.A. Bakopoulos, "Quality Improvement of Individual Cores of Distribution Transformers Using Decision Trees," Int. Journal of Engineering Intelligent Systems, vol. 6, no. 3, September 1998, pp. 141-146.

[11] N. Logothetis, "Establishing a Noise Performance Measure," The Statistician, vol. 38, 1989, pp. 155-174. 